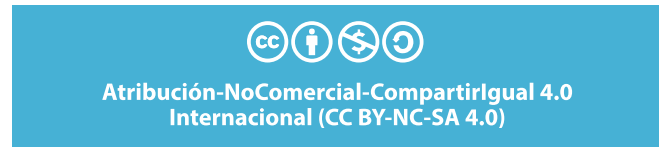

DOI: http://dx.doi.org/10.20983/reij.2021.2.4
Juan Manuel Saldaña Pérez ${ }^{1}$
FECHA DE ENVío: 30 de noviembre 2020

FECHA DE ACEPTACIÓN: 18 de marzo 2021

\title{
PANEL LABORAL GENERAL Y MECANISMO LABORAL DE RESPUESTA RÁPIDA EN INSTALACIONES ESPECÍFICAS DEL T-MEC
}

\author{
General Labor Panel and Rapid Response Labor Mechanism \\ in Specific Facilities of the T-MEC
}

\section{Resumen:}

En este trabajo de investigación se analizaron las diversas obligaciones laborales pactadas en el T-MEC, así como los procedimientos arbitrales previstos tanto en el Protocolo por el que se sustituye al TLCAN por el T-MEC del 30 de noviembre de 2018 como en el Protocolo Modificatorio del T-MEC del 10 de diciembre de 2019. Con especial cuidado se examinó lo escrito con letra chica en las Notas al pie de página de este último, donde se incluyeron importantes cambios. Se estudió el Panel Laboral General, su competencia, los requisitos que cualquiera de las Partes debe cumplir para presentar una reclamación, la carga probatoria para la demandada y la adopción de medidas de represalia, en su caso. Adicionalmente, se analizó el denominado Mecanismo Laboral de Respuesta Rápida en Instalaciones Específicas México Estados Unidos, su competencia, la diferencia en cuanto a los requisitos que debe cumplir cada una de las Partes para presentar una reclamación, la carga de la prueba para la demandada y las sanciones que se pueden imponer. Finalmente se analizaron los cinco agregados laborales adscritos a la embajada o al consulado de Estados Unidos para vigilar y hacer cumplir las obligaciones laborales de México, los cuales, aunque no fueron pactados en el T-MEC, están previstos en la United States-Mexico-Canada Agreement Implementation Act HR5430.

Palabras clave: resolución; disputas; laborales; T-MEC.

\section{Abstract:}

In this research work, the various labor obligations agreed in the T-MEC were analyzed, as well as the arbitration procedures provided for both in the Protocol that replaces NAFTA by the T-MEC of November 30, 2018 and in the Protocol Modification of the T-MEC of December 10, 2019. With special care, what was written in fine print in the footnotes of the latter was examined, where important changes were included. The General Labor Panel was studied, its competence, the requirements that any of the Parties must meet to file a claim, the burden of proof for the defendant and the adoption of retaliatory measures, if applicable. Additionally,

1 Profesor de la Facultad de Derecho de la Universidad Nacional Autónoma de México. Magistrado Presidente de la Primera Sala Especializada en Materia de Comercio Exterior del Tribunal Federal de Justicia Administrativa. Miembro del Sistema Nacional de Investigadores, nivel 1 del Conacyt. Correo electrónico: juansaldanaperez@hotmail. com. ORCID: 0000-0003-0345-2072 
the so-called Rapid Response Labor Mechanism in Specific Facilities Mexico United States was analyzed, its competence, the difference in terms of the requirements that each of the Parties must meet to present a claim, the burden of proof for the defendant and the sanctions that can be imposed. Finally, the five labor attachés assigned to the United States embassy or consulate to monitor and enforce Mexico's labor obligations were analyzed, which, although they were not agreed upon in the T-MEC, are provided for in the United States-Mexico- Canada Agreement Implementation Act HR5430.

Keywords: settlement; disputes; labor; USMCA.

\section{INTRODUCCIÓN}

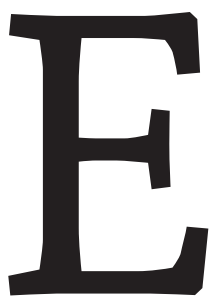

s del dominio público que el gobierno norteamericano impusiera la actualización del Tratado de Libre Comercio de América del Norte de 1994 (TLCAN). Desde antes del inicio de las negociaciones, el presidente Trump amenazó con abandonarlo si no se satisfacían sus demandas por considerar que era "el peor acuerdo comercial de la historia”.

Incluso durante la negociación, Trump manifestó que el TLCAN había sido un desastre para Estados Unidos por diversos motivos, como el robo de las inversiones y empleos, el dumping laboral e injustas reglas de origen del sector automotriz, lo que había provocado un gran "déficit en la balanza comercial con México”. Además, por motivos de seguridad nacional, justificó la necesidad de construir un "muro fronterizo" para frenar la migración y el narcotráfico, entre otras amenazas, calificando a México como el país más peligroso del mundo.

Durante décadas Estados Unidos ha acumulado un déficit comercial grande y creciente con el resto del mundo, incluido México, especialmente después de la aprobación del TLCAN en 1994. El comercio entre Estados Unidos y México creció con el TLCAN, pero contrario a las predicciones y la teoría estándar del comercio, el 
tratado no produjo ganancias salariales notables en México.

El TLCAN suponía un crecimiento de empleo, salarios y productividad en los trabajadores de los tres países; no obstante, esto no ha sucedido. No solamente se ha ampliado la brecha salarial y productiva, sino que no ha habido un incremento en la creación de empleos y en todos los sectores económicos del país se ha observado la constante pérdida de empleos formales. ${ }^{2}$

Estudios revelan que el déficit comercial de Estados Unidos ha crecido más lentamente con países que han implementado normas laborales más estrictas. Entre 2000 y 2007, la brecha entre las exportaciones y las importaciones de Estados Unidos aumentaron más rápidamente para países con menor o inexistente protección laboral que con aquellos países con algunos o fuertes derechos laborales.

$\mathrm{Al}$ respecto, Weller considera que mejores estándares laborales en México podrían disminuir el déficit en la balanza comercial de Estados Unidos. Lo anterior debido a que se incrementarían los ingresos de los trabajadores mexicanos, repercutiendo positivamente en el aumento de las exportaciones estadounidenses, y reduciría la ventaja del bajo costo de la producción en México por los bajos salarios

2 Carrillo Huerta y otros, La renegociación del TLCAN y sus posibles impactos en el desarrollo regional del país. En: Las relaciones México-Estados Unidos en la coyuntura actual. Carrillo Huerta, Mario Miguel, Coordinador, Consejo Latinoamericano de Ciencias (Clacso), Puebla, México, 2017, p. 281. y condiciones laborales, puesto que los trabajadores no podrían ser mal pagados, lo que disminuiría la cantidad de importaciones de productos mexicanos a Norteamérica. ${ }^{3}$

En este orden de ideas, en la campaña de 2016, Hillary Clinton abandonó su apoyo al Acuerdo Transpacífico de Cooperación Económica (TTP-TIPAT) y prometió revisar el TLCAN y defender los beneficios de los trabajadores estadounidenses en las negociaciones internacionales. ${ }^{4}$

Posteriormente, el 23 de enero de 2017, Donald Trump, inmediatamente después de asumir la presidencia, firmó una orden ejecutiva para retirar a Estados Unidos del TTP al considerar que era "un desastre potencial para el país” y dañaría al sector manufacturero. ${ }^{5}$

En el 2018, México suscribió el Tratado Integral y Progresista de la Asociación

3 Weller, Christian E. The Future of North American Trade Policy. Lesson from NAFTA. Boston University, The Frederick S. Pardee Center for the Study of Longer-Range Future, noviembre 2009, pp. 71, 72 y 75.

4 Puyana, Alicia. Del Tratado de Libre Comercio de América del Norte al Acuerdo México-Estados Unidos-Canadá. ¿ Nuevo Capítulo de Integración México Estados Unidos?. El Trimestre Económico, LXXXVII(3), núm. 347, julio-septiembre de 2020, p. 636.

5 El TPP (Trans-Pacific Partnership) fue uno de los temas centrales en materia de comercio exterior del gobierno del expresidente Barack Obama, que invirtió siete años en su negociación. Los países miembros representaban un tercio del comercio internacional y sumaban unos 800 millones de habitantes. BBC Mundo. Donald Trump retira a Estados Unidos del TPP, el Acuerdo Transpacífico de Cooperación Económica. https://www.bbc.com/mundo/ noticias-internacional-38723381 
Transpacífico (TIPAT), ${ }^{6}$ donde se comprometió a reformar las leyes secundarias que permitan el cumplimiento de obligaciones pactadas en el Convenio 98 de la Organización Internacional del Trabajo (OIT), adoptar derechos fundamentales reconocidos por este organismo y fortalecer la justicia laboral, convirtiéndose así, en el antecedente directo del capítulo laboral del nuevo Tratado México, Estados Unidos y Canadá (T-MEC).

Con el objeto de cumplir con los compromisos adquiridos en el Comité de Libertad Sindical de la OIT y en la negociación del TIPAT, en febrero de 2017 se reformaron los artículos 107 y 123 de la Constitución, sentando las bases para modernizar el sistema de justicia laboral y transformar el régimen sindical y de negociación colectiva en México. En septiembre de 2018, el senado aprobó el Convenio 98 de la OIT, relativo al derecho de sindicación y negociación colectiva, adoptado por México desde 1949. ${ }^{7}$

Después de más de un año de constantes amenazas del presidente Trump y de difíciles negociaciones, ${ }^{8}$ el 30 de noviembre del 2018, Estados Unidos, México y Canadá (las Partes) suscribieron el Proto-

6 Decreto Promulgatorio del TIPAT, D.O.F. 29 de noviembre de 2018.

7 Banco de México, Consideraciones sobre la Reforma Laboral de 2019, Extracto del Informe Trimestral enero-marzo 2019, Recuadro 4, pp. 35-37, mayo 2019.

8 Las pláticas iniciaron de manera formal desde el 15 de agosto de 2017. colo por el que se Sustituye el TLCAN por el T-MEC, ${ }^{9}$ donde, en el Capítulo 23 se incluyeron las obligaciones y derechos laborales previstos, tanto en el TIPAT, como en los diversos tratados de la OIT, así como un mecanismo de solución de diferencias para hacer valer su cumplimiento. ${ }^{10}$

Sin embargo, aun cuando los tres países habían suscrito el nuevo acuerdo comercial, faltaba la aprobación de sus correspondientes órganos internos, y particularmente del Congreso norteamericano dominado por el partido demócrata que condicionó su voto aprobatorio a que México modificara su legislación en materia laboral conforme a la referida reforma constitucional de 2017.

En respuesta a las exigencias de Estados Unidos, en el mes de mayo de 2019,11 México modificó su legislación laboral adecuándola a la Constitución y a los compromisos asumidos en diversos tratados,

9 Decreto que aprueba el Protocolo por el que se sustituye el TLCAN por el T-MEC del 30 de noviembre del 2018, Senado de la República, D.O.F. 29 de julio de 2019.

10 Es importante mencionar que, derivado de la negociación del TLCAN de 1994, se celebraron dos Acuerdos Paralelos, uno en materia ambiental y otro en materia laboral. En este último, los tres países incluyeron compromisos relativos al cumplimiento de sus leyes laborales; sin embargo, estos acuerdos paralelos no formaron parte del tratado y su cumplimiento fue limitado.

11 Decreto por el que se reforman, adicionan y derogan diversas disposiciones de la ley Federal del Trabajo, de la Ley Orgánica del Poder Judicial de la Federación, de la Ley Federal de la Defensoría Pública, del Instituto Nacional de la Vivienda para Trabajadores y de la Ley del Seguro Social, en materia de Justicia Laboral, Libertad Sindical y Negociación Colectiva. D.O.F. 01 de mayo de 2019. 
incluido el futuro T-MEC. Estas reformas, en términos generales, se pueden resumir en los siguientes grandes objetivos en beneficio de los trabajadores: ${ }^{12}$

Primero. Garantizar una mayor libertad y democracia para los trabajadores en la elección de sus representantes sindicales, aumentar la transparencia y la rendición de cuentas de los sindicatos.

Segundo. Hacer más expedito el sistema de impartición de justicia laboral, creando tribunales dependientes del Poder Judicial y favoreciendo la conciliación.

Tercero. Prevenir cualquier tipo de discriminación en el trabajo.

Cuarto: Regular los derechos de los trabajadores del campo y del hogar.

En efecto, el partido demócrata de Estados Unidos pidió algunos cambios a la legislación interna mexicana, principalmente tratándose de la democracia sindical, los salarios a los trabajadores y el manejo de la impartición de justicia. En realidad, estos cambios eran verdaderamente necesarios, sobre todo, porque los sindicatos mexicanos no informaban a sus integrantes de lo que hacían sus líderes sindicales, eligiéndose y reeligiéndose los

12 Banco de México, Consideraciones sobre la Reforma Laboral de 2019, Extracto del Informe Trimestral enero-marzo 2019, Recuadro 4, pp. 35-37, mayo 2019. dirigentes sin tomar en cuenta a los empleados y con una espantosa corrupción que hicieron millonarios a esos líderes. De igual forma, los tribunales laborales se han conducido bajo esquemas organizativos deprimentes, dependiendo del mismo poder ejecutivo, no del judicial, y de igual forma, sin considerar a los trabajadores, especialmente en los sindicatos corruptos que dependían del presidente, por medio de la Secretaría del Trabajo. Era urgente realizar estos cambios y ajustes. ${ }^{13}$

Una vez realizadas las reformas a las leyes secundarias en materia laboral, favoreciendo a millones de trabajadores de todo México, el 10 de diciembre del 2019, los tres países firmaron el Protocolo Modificatorio del T-MEC (Protocolo Modificatorio), donde se incluyeron importantes cambios y adiciones al texto original del 2018, incluyendo un mecanismo especial de solución de controversias en materia de libertad de asociación y negociación colectiva en instalaciones específicas. ${ }^{14}$

13 Silva Silva, Jorge Alberto, Relaciones del Tráfico Jurídico Internacional en el Derecho Mexicano del Trabajo, Primera edición, Academia Mexicana de Derecho Internacional Privado y Comparado, 2021, p. 255. http://.amedip.org/

14 Las modificaciones acordadas por el negociador único de México se refieren a diversos capítulos y entrarán en vigor en la misma fecha que el T-MEC. En el caso de Estados Unidos, se expidió la Ley de Implementación respectiva. Cruz Barney, Oscar, La Solución de Controversias en Materia Laboral en el Tratado entre los Estados Unidos Mexicanos y los Estados Unidos de América y Canadá, Instituto de Investigaciones Jurídicas de la UNAM, Opiniones Técnicas sobre Temas de Relevancia Nacional, núm., 18, p. 27. 
Tres días después, el 13 de diciembre, el Congreso norteamericano aprobó tanto el Protocolo que Sustituye el TLCAN por el T-MEC como el Protocolo Modificatorio, y para darles validez e incorporarlos a su sistema jurídico, expidió una ley nacional denominada United States-Mexico-Canada agreement implementation act HR5430 (USMCA Implementation Act). ${ }^{15}$

Por su parte, el 29 de junio de 2020, el senado mexicano aprobó tanto el Protocolo que sustituye el TLCAN por el T-MEC como el Protocolo Modificatorio. ${ }^{16}$ En virtud de que ambos instrumentos integran el tratado comercial, en lo sucesivo me referiré a uno u otro, o en su conjunto al T-MEC, según proceda.

En resumidas cuentas, con el propósito de lograr la aprobación del Congreso norteamericano, Trump aceptó las propuestas de los demócratas en materia laboral. En México, López Obrador consideró las propuestas laborales en el T-MEC como la

15 An Act to implement the Agreement between the United States of America, the United Mexican States, and Canada attached as an Annex to the Protocol Replacing the North American Free Trade Agreement, april 18 ${ }^{\text {th }}$, 2020, H.R. 5430 (Enrolled Bill). One Hundred Sixteenth Congress of United States of America.

16 Decreto Promulgatorio del Protocolo por el que se Sustituye el TLCAN por el T-MEC, hecho en Buenos Aires, el 30.11.2018; del Protocolo Modificatorio al T-MEC, hecho en la Ciudad de México el 10.12.2019; de seis acuerdos paralelos entre el Gobierno de México y el Gobierno de Estados Unidos, celebrados por intercambio de cartas fechadas en Buenos Aires el 30.11.2018 y de dos acuerdos paralelos entre el Gobierno de México y el Gobierno de Estados Unidos, celebrados en la Ciudad de México el 10 de diciembre de 2019, DOF, 29 de junio de 2020. vía para desactivar la oposición a su política de distribución del ingreso, asegurar la reforma laboral de 2018 y eliminar, o al menos paliar, la pérdida acumulada desde 1976 del valor adquisitivo del salario mínimo real. Las autoridades mexicanas muestran optimismo y enfatizan el sentido social del nuevo tratado que busca elevar, o al menos revertir, la caída de las remuneraciones y el bienestar de la clase trabajadora. En tanto que el sector privado difiere un tanto al considerar que algunas medidas podrían encarecer la producción y reducir las exportaciones. ${ }^{17}$

En seguida se analizan las obligaciones que en materia laboral asumieron los tres países. Posteriormente se estudia el Panel laboral general y el MLRR en instalaciones específicas previsto en el T-MEC y finalmente se examinan los cinco agregados laborales adscritos a la embajada o al consulado de Estados Unidos en México, creados en la USMCA Implementation Act.

\section{Obligaciones laborales}

En el Capítulo 23 del T-MEC, México, Estados Unidos y Canadá (las Partes) asumieron las siguientes obligaciones en materia laboral: derechos laborales, no derogación, aplicación de leyes, violencia contra trabajadores, trabajo forzoso u obligatorio, trabajadores migrantes, discrimina-

17 Puyana, Alicia, Ob. Cit., pp. 655, 656 y 657. 
ción en el centro de trabajo y justicia laboral.

En el artículo 23.3, los tres países se comprometieron a adoptar, mantener (no derogar) y aplicar en sus leyes, regulaciones y prácticas que deriven de estas, los siguientes derechos laborales tal y como se establecen en la Declaración de la OIT sobre los Derechos en el Trabajo:

I. Libertad de asociación (incluido el derecho de huelga), reconocimiento efectivo del derecho a la negociación colectiva;

II. Eliminación de todas las formas de trabajo forzoso u obligatorio;

III. Abolición efectiva del trabajo infantil,

IV. Eliminación de la discriminación en el empleo y ocupación (salarial, de género, acoso, etc.), y

V. Condiciones aceptables de trabajo (salarios mínimos, horas de trabajo, seguridad y salud en el trabajo).

Es necesario hacer notar que los compromisos asumidos son desbalanceados y obligan más a México que a los Estados Unidos. Por ejemplo, México ha suscrito las nueve resoluciones fundamentales y vinculantes de la OIT y los Estados Unidos solo dos. ${ }^{18}$

De igual manera, se obligaron a no renunciar ni ofrecer renunciar a aplicar o derogar sus leyes o regulaciones que im-

18 Ibidem, p. 658. plementen los Derechos Laborales referidos en el artículo 23.3 de una manera que afecte el comercio o la inversión entre las partes. ${ }^{19}$

Además, asumieron el compromiso de no dejar de aplicar efectivamente sus leyes laborales a través de un curso de acción o inacción sostenido (constante o continuo) o recurrente (periódico o repetido) en una manera que afecte el comercio o la inversión entre las Partes. ${ }^{20}$

Convinieron que abordarán de manera efectiva los incidentes de violencia, amenazas e intimidación contra trabajadores directamente relacionados con el ejercicio o el intento de ejercer los derechos laborales previstos en el artículo 23.3, en una manera que afecte el comercio o la inversión entre las Partes. ${ }^{21}$

También se comprometieron a prohibirla importación de mercancías producidas, en su totalidad o en parte, por trabajo forzoso u obligatorio, incluido el trabajo infantil bajo dichas condiciones, y a establecer un mecanismo de cooperación trinacional para identificar dichas mercancías. ${ }^{22}$

Al implementar el Artículo 23.3 (Derechos Laborales) cada Parte asegurará que los trabajadores migrantes estén protegi-

19 Artículo 23.4 del Protocolo que sustituye el TLCAN por el T-MEC y la Nota 9 del Protocolo Modificatorio.

20 Artículo 23.5 del Protocolo que sustituye el TLCAN por el T-MEC y la Nota 10 del Protocolo Modificatorio.

21 Artículo 23.7 del Protocolo que sustituye el TLCAN por el T-MEC.

22 Artículos 23.6 y 23.12.5(c) del Protocolo que sustituye el TLCAN por el T-MEC. 
dos conforme a sus leyes laborales, sean o no nacionales de la parte. ${ }^{23}$

Para eliminar la discriminación en los centros de trabajo, se obligaron a implementar políticas que incluyan los siguientes aspectos: igualdad de la mujer, nacimiento o la adopción de infantes, cuidado de los miembros de la familia, igualdad salarial, acoso, orientación sexual y licencias, entre otros. ${ }^{24}$

Finalmente, los tres países se comprometieron a crear tribunales imparciales e independientes para la aplicación de sus leyes laborales, mediante procedimientos justos, equitativos, transparentes, expeditos, en apego a la garantía de audiencia y al debido proceso. ${ }^{25}$

\section{Panel laboral general}

El Capítulo XX del TLCAN relativo a la solución de diferencias, se convirtió en el Capítulo 31 del T-MEC con algunas modificaciones y adiciones, entre las que destacan el nombramiento del presidente del panel y panelistas (artículo 31.9) y la creación de tres mecanismos arbitrales en materia laboral.

El Capítulo 31 establece un panel para resolver controversias México, Estados Uni-

23 Artículo 23.8 del Protocolo que sustituye el TLCAN por el T-MEC.

24 Artículo 23.9 del Protocolo que sustituye el TLCAN por el T-MEC.

25 Estos tribunales pueden ser administrativos, cuasi judiciales, judiciales o laborales, conforme al ordenamiento jurídico de cada Parte. Artículo 23.10 del Protocolo que sustituye el TLCAN por el T-MEC. dos y Canadá, respecto de cualquier materia del tratado, incluyendo diferencias relativas al incumplimiento de cualquier obligación laboral (Panel Laboral General), salvo en los casos de excepción que se indican en el mismo tratado, tales como las controversias en materia de inversión, dumping y subvenciones, entre otras.

De igual manera incluye dos Paneles o Mecanismos Laborales de Respuesta Rápida en Instalaciones Específicas (MLRR o Mecanismo de Respuesta Rápida), uno México Estados Unidos y otro México Canadá (Anexos 31 A y 31 B). Es importante señalar que ambos MLRR son similares y no se incluyó un instrumento arbitral de esta naturaleza entre Estados Unidos y Canadá.

La competencia de un Panel Laboral General es amplia, puesto que revisa el incumplimiento de cualquiera de las obligaciones laborales previstas en Capítulo 23. En cambio, un Mecanismo de Respuesta Rápida tiene competencia reducida para revisar, exclusivamente, si existe Denegación de Derechos de los trabajadores en una instalación específica.

Es importante destacar que un Panel Laboral General y un Mecanismo de Respuesta Rápida no resuelven controversias laborales entre trabajadores y patrones, ya que estos tribunales arbitrales tienen como misión la solución de conflictos entre las partes, esto es, entre Estados. 
En consecuencia, los conflictos laborales entre trabajador y empleador o patrón, se resuelven ante los tribunales nacionales de cada una de las Partes.

\section{Integración}

Conforme a lo previsto en el artículo 2011 del TLCAN, las partes tenían que acordar el nombramiento del presidente y de no alcanzar acuerdo, una de las electas por sorteo lo debía designar.

Además, se estableció un mecanismo de nombramiento o selección cruzada de panelistas. Dentro de los quince días siguientes a la elección del presidente, cada Parte debía seleccionar dos panelistas ciudadanos de la otra Parte. En el caso de que una Parte no seleccionara a sus panelistas, se designarían por sorteo de entre los miembros de la lista que fueran ciudadanos de la otra Parte contendiente.

Sin embargo, el referido artículo 2011 del TLCAN contenía una "cláusula arbitral patológica” o laguna legal, puesto que no indicaba la manera como se nombraría al presidente de panel cuando la Parte electa por sorteo (demandada), debiéndolo nombrar, no lo nombraba.

Lo anterior, en la práctica obstaculizó e impidió la integración del panel y la solución de controversias, tal es el caso de la solicitud de México para la constitución de un panel por la negativa de Estados Unidos de permitir la importación de los excedentes de azúcar mexicana a territo- rio norteamericano, violando lo establecido en el Anexo 703.2 del TLCAN, lo cual derivó en largos y costosos litigios arbitrales internacionales, tanto en el ámbito del TLCAN como de la OMC, en perjuicio del Estado mexicano. ${ }^{26}$

En el caso del azúcar, Estados Unidos (parte demandada) se negó a nombrar presidente. El panel solicitado por México jamás se integró y la controversia nunca se resolvió. Este conflicto tampoco se pudo someter a arbitraje del Órgano de Solución de Diferencias de la Organización Mundial del Comercio (OSD/OMC), ya que un procedimiento arbitral es excluyente del otro.

En diferentes foros, antes y durante la negociación del T-MEC expresamos la necesidad de establecer con claridad el "procedimiento para nombrar al presidente de panel y los panelistas cuando una parte (demandada) electa por sorteo no los nombra".

El texto original del artículo del 31.9 del Protocolo que sustituye el TLCAN por el T-MEC, firmado en el 2018, adoptó íntegra-

26 Véase Decisión Final del Panel Binacional. Sobre la imposición de cuotas compensatorias impuestas a las importaciones de Jarabe de Maíz de Alta Fructosa (JMAF) originarias de los Estados Unidos de América, 03 de agosto de 2001. Caso Mex-USA-98-1904-01; Informe del Órgano de Apelación del caso México-Medidas Fiscales sobre los refrescos y otras bebidas, WT/DS308/AB/R, 06 de marzo de 2006; Cargill, Inc. C. México (Escrito de duplica), CIADI, Mecanismo complementario, Washington, D. C., Caso Núm. ARB (AF)/05/20.08.2020; y Cargill, Inc. C. México (Laudo), CIADI, Mecanismo complementario, Washington, D.C., Caso Núm. ARB (AF)/05/2. Fecha de envío a las partes: 18 de septiembre de 2009. 
mente la mencionada "cláusula arbitral patológica” del artículo 2011 del TLCAN.

Un año más tarde, el 10 de diciembre del 2019, los tres países firmaron el Protocolo Modificatorio, donde se adicionaron los incisos 1.c, 1.f, 2.c y 2.f del artículo 31.9 con el propósito de eliminar la referida laguna legal.

Artículo 31.9 del Protocolo Modificatorio

1. Si son dos las Partes contendientes, los siguientes procedimientos aplicarán:

(b) [...] Si las Partes contendientes no logran decidir la designación del presidente [...], la Parte contendiente, electa por sorteo, elegirá como presidente, dentro de un plazo de cinco días, a un individuo que no sea nacional de esa Parte.

(c) Si la Parte demandada se niega a participar o no se presenta para el procedimiento de selección por sorteo, la Parte reclamante seleccionará a un individuo de la lista que no sea nacional de esa Parte. (f) [...] Si la Parte demandada se niega a participar o no se presenta para el procedimiento de selección por sorteo, la Parte reclamante seleccionará a dos individuos de la lista que sean nacionales de la Parte reclamante [énfasis añadido].

Sin embargo, la reforma al artículo 31.9 del Protocolo Modificatorio no resolvió el problema, ya que el texto actual no indica el procedimiento para nombrar al presidente o árbitros cuando la parte deman- dada seleccionada por sorteo no realiza su nombramiento.

Este supuesto se presenta cuando la parte demandada sí participa y se presenta al sorteo, tan es así que como resultado del sorteo es "electa" para realizar los nombramientos correspondientes; sin embargo, simplemente no hace el o los nombramientos de presidente o panelistas.

La experiencia nos demuestra que cuando se presenta una controversia, la parte demandada (Estados Unidos) aprovecha cualquier ambigüedad en su favor. Por lo anterior, es conveniente que en la primera oportunidad se modifique el artículo 31.9, a efecto de establecer con claridad que "cuando la Parte demandada electa por sorteo no nombre al presidente o a los panelistas (árbitros), estos serán designados por la Parte reclamante”.

\section{Consultas y procedimiento}

Las Partes realizarán todos los esfuerzos a través de la cooperación y el diálogo para alcanzar una solución mutuamente satisfactoria de cualquier asunto que surja conforme al Capítulo 23.

La Parte reclamante debe solicitar a la otra parte la realización de consultas laborales. De no resolverse el asunto dentro de los 75 días posteriores a la solicitud, puede solicitar la instalación de un Panel Laboral General por violación o incumplimien- 
to a alguna de las siguientes Obligaciones laborales. ${ }^{27}$

- Derechos laborales,

- No derogación,

- Aplicación de las leyes laborales,

- Violencia contra los trabajadores.

El incumplimiento o violación a cualquiera de las referidas Obligaciones Laborales debe ser de una manera que afecte el comercio o la inversión entre las Partes, lo anterior conforme a lo previsto en las Notas al pie de página 4 del Artículo 23.1 (Derechos Laborales); 8 del Artículo 23.4 (No Derogación); 11 del Artículo 23.5 (Aplicación de las Leyes Laborales) y 13 del Artículo 23.7 (Violencia contra los Trabajadores) del Protocolo Modificatorio..$^{28} \mathrm{El}$ incumplimiento es "de una manera que afecte el comercio y la inversión entre las partes" si involucra:

a) A una persona o industria que produce una mercancía comerciada entre las partes.

b) A una persona o industria que suministra un servicio comerciado entre las partes.

27 Artículos 23.17.1, 23.17.8, 23.17.12 y 31.6 del Protocolo Modificatorio del T-MEC. Los artículos 23.17.8 y 31.6 del protocolo que sustituye el TLCAN por el el T-MEC establecía un plazo de 30 días posteriores a la solicitud de consultas para solicitar el panel laboral general.

28 Notas 4, 8, 11, 13 del Protocolo Modificatorio. c) A una persona o una industria que produce una mercancía que compite en el territorio de una parte con una mercancía o un servicio de otra parte.

d) A una persona o una industria que suministra un servicio que compite en el territorio de una parte con un servicio de otra parte.

e) A una persona o una industria que tiene una inversión en el territorio de la parte que ha incumplido con esta obligación.

Para efectos de la solución de controversias un Panel Laboral "supondrá" (asumirá) ${ }^{29}$ que un incumplimiento es de una manera que afecte el comercio y la inversión entre las Partes, a menos que la parte demandada demuestre lo contrario, conforme a lo establecido en las Notas al pie de página números 5 del artículo 23.1 (Derechos laborales); 9 del artículo 23.4 (No derogación); 12 del artículo 23.5 (Aplicación de las leyes laborales) y 14 del artículo.

29 Es importante señalar que el texto del Protocolo Modificatorio firmado por los tres países y publicado por la Secretaría de Relaciones Exteriores dice "asumirá”, en tanto que el texto de Protocolo Modificatorio publicado en el DOF del 30 de junio de 2020 dice "supondrá". Véase Secretaría de Relaciones Exteriores. Protocolo Modificatorio al Tratados entre los Estados Unidos Mexicanos, los Estados Unidos de América y Canadá, publicado el 11 de diciembre de 2019. Consultado el 14 de noviembre del 2020. https://www.gob.mx/sre/documentos/protocolo-modificatorio-al-tratado-entre-los-estados-unidos-mexicanos-los-estados-unidos-de-america-y-canada 
23.7 (Violencia contra los trabajadores) del Protocolo Modificatorio. ${ }^{30}$

Notas 5, 9, 12 y 14 del Protocolo Modificatorio:

Para efectos de la solución de controversias, un panel supondrá que un incumplimiento es de una manera que afecte el comercio o la inversión entre las Partes, a menos que la Parte demandada demuestre lo contrario [énfasis añadido].

Es importante reiterar que algunos de los compromisos de mayor relevancia o importancia para México en el T-MEC se escribieron con "letra chica" en las Notas al pie de página del Protocolo Modificatorio, donde se cambió el texto de la Nota 4 y se incluyeron nuevas Notas 5, 9,12 y 14 del Capítulo 23.

La Nota 4 del Protocolo que sustituye el TLCAN por el T-MEC decía con claridad que la "reclamante" tenía la carga de la prueba para demostrar que la demandada había incumplido con alguno de los derechos laborales enumerados en el Artículo 23.3 (Derechos Laborales) de manera que afecta el comercio y la inversión entre las Partes.

30 Notas 4 y 5 del artículo 23.1 (Derechos laborales); notas 8 y 9 del artículo 23.4 (No derogación); Notas 11 y 12 del artículo 23.5 (Aplicación de las leyes laborales); y notas 13 y 14 del artículo. 23.7 (Violencia contra los trabajadores).
Nota 4 del artículo 23.3 del Protocolo que Sustituye TLCAN por T-MEC:

Para establecer una violación de una obligación conforme a los párrafos 1 o 2 [artículo 23.3], una Parte debe demostrar que la otra Parte no ha cumplido con adoptar o mantener una ley, regulación o práctica de una manera que afecte el comercio o la inversión entre las Partes... ${ }^{31}$ [paréntesis añadido].

Las nuevas Notas 5, 9, 12 y 14 del Protocolo Modificatorio trasladan la carga de la prueba del actor al demandado al señalar que un panel (Panel Laboral General y Mecanismo de Respuesta Rápida) "supondrá" que un incumplimiento de las Obligaciones laborales (Derechos laborales, No derogación, Aplicación de leyes laborales y Violencia contra trabajadores) afecta el comercio y la inversión entre las partes, a menos que la demandada demuestre lo contrario.

Suponer, del latín supponere, significa "Considerar como cierto algo a partir de los indicios que se tienen" o "considerar como cierto algo o real algo que no lo es o no tiene porqué serlo". ${ }^{32}$

En otras palabras, un Panel Laboral General debe considerar que una violación a cualquier obligación laboral afecta el comercio o la inversión entre las partes, aun-

31 Nota 4 del artículo 23.3 del Protocolo Modificatorio del T-MEC del 10.12.2019, D.O.F. 26.06.2020.

32 Voz: suponer, Diccionario de la Lengua Española, Real Académia Española, actualización 2020. 
que no la afecte. Lo anterior implica una gran ventaja para la parte reclamante que puede iniciar procedimientos de panel frívolos sin presentar un mínimo de pruebas en perjuicio de la parte demandada, quien tiene la carga probatoria de demostar que el incumplimiento a cualquiera de las obligaciones laborales no afecta el comercio y la inversión entre las partes. Lo anterior se traduce en una carga procesal muy costosa para la defensa, tanto en recursos económicos como humanos.

Es del dominio público que la materia laboral es uno de los temas incluidos por Estados Unidos en el T-MEC, por lo que, seguramente, en la mayoría de los casos México será la parte demandada, así lo han expresado de manera perisistente diferentes medios de comunicación. ${ }^{33}$

\section{Informe final}

El Panel Laboral General debe presentar su Informe Final a las partes dentro de los 180 días contados a partir de la designación del último panelista, el cual podrá constatar:

a) Que una medida es incompatible con las obligaciones de una parte; 0

b) Que una parte no ha cumplido sus obligaciones.

33 Véase Castañeda, Jorge, El T-MEC y la reforma laboral, El Financiero, 12 de abril de 2019 y De la Rosa, Eduardo, Administración de Biden podría abrir casos contra México en T-MEC: Kenneth Smith, Peródico Milenio, México, 11 de noviembre de 2020.
Las Partes deben acordar la solución de la controversia en los 45 días siguientes al Informe Final. De no alcanzar un acuerdo, la Parte reclamante podrá suspender beneficios de efecto equivalente a la Parte demandada. ${ }^{34}$

\section{Mecanismo Laboral de Respuesta Rápida}

Los dos MLRR ${ }^{35}$ México Estados Unidos (Anexo 31 "A") y México Canadá (Anexo 31 “B”), creados en el Protocolo Modificatorio son similares y pueden resolver una controversia en 60 días sin verificación o en 80 días con verificación. Es importante destacar que no se estableció un Mecanismo de Respuesta Rápida Estados Unidos Canadá.

El MLRR tiene como finalidad garantizar la reparación de una negación de los derechos de libre asociación y de negociación colectiva de los trabajadores en una instalación cubierta, esto es, en una empresa o una planta que:

(i) Produce una mercancía o suministra un servicio comerciado entre las partes;

(ii) Produce una mercancía o suministra un servicio que compite en el territo-

34 Artículo 31.17: 31.18 y 31.19 del Protocolo que sustituye el TLCAN por el T-MEC.

35 Es importante considerar que no se estableció un mecanismo laboral de respuesta rápida en instalaciones específicas Estados Unidos Canadá. 
rio de una Parte con una mercancía o un servicio de otra parte, y es una instalación en un Sector Prioritario; (31 A.13 y 31 A.15).

Un Sector Prioritario es aquel que involucra minería, suministra servicios y produce mercancías manufacturadas. Las partes deben revisar anualmente la lista de sectores prioritarios y determinar si se agrega algún sector a la lista. Conforme a lo previsto en el artículo 31 A.15 y Nota al pie de página 4 del Protocolo Modificatorio, los sectores prioritarios actualmente son: ${ }^{36}$

- Componentes aeroespaciales,

- autos y autopartes,

- productos cosméticos,

- mercancías industriales horneadas (panadería industrial),

- acero y aluminio,

- vidrio,

- cerámica,

- plástico,

- forjas y

- cemento.

Es importante destacar que la Sección 713 de USMCA Implementation Act establece una lista de subsectores prioritarios que también incluye:

- electrónica,

36 Artículos 31 A.13 y 31 A.15 del Protocolo Modificatorio.
- centros de llamada, y

- montaje automático.

\section{Consultas, revisión voluntaria y recla- mación}

Antes de solicitar el establecimiento de un Mecanismo de Respuesta Rápida, la reclamante debe intentar solucionar la controversia con la demandada mediante cooperación, consultas y revisión voluntaria. ${ }^{37}$

Para tal efecto, solicitará a la demandada que revise si existe Denegación de Derechos. Desde ese momento, la reclamante puede retrasar la liquidación final de las cuentas aduaneras ${ }^{38}$ relacionadas con el ingreso de mercancías procedentes de la planta o empresa objeto de revisión.

Si la demandada no realiza la Revisión voluntaria, o como resultado de esta, decide que no existe Denegación de Derechos, la reclamante puede solicitar un MLRR. En caso de que la Parte demandada acepte que existe una Denegación de Derechos, ambas Partes realizarán consultas por diez días para acordar una reparación y fijar un plazo para su cumplimiento, sin interrumpir el comercio.

37 Artículo 23.17.2 del Protocolo que sustituye el TLCAN por el T-MEC.

38 La cuenta aduanera es un instrumento operado por instituciones de crédito o casas de bolsa autorizadas, en la cual se depositan las contribuciones generadas en la importación definitiva de aquellos bienes que vayan a exportarse en el mismo estado en un plazo que no exceda de un año, prorrogable por dos años más. Artículo 86 de la Ley Aduanera y Regla 1.6.25 de las Reglas Generales de Comercio Exterior 2019. 
Si al concluir el plazo para cumplir la reparación acordada, la Parte reclamante considera que la negación de derechos no ha sido reparada, notificará a la Parte demandada su intención de imponer medidas de reparación quince días antes de su aplicación, en cuyo caso, la Parte demandada puede solicitar un Panel Laboral de Respuesta Rápida para que determine si la negación de derechos persiste.

La Parte reclamante puede solicitar un Mecanismo de Respuesta Rápida en dos momentos: a) durante las consultas, en cuyo caso, emitirá una solicitud de verificación después de concluidas, o b) concluidas las consultas, si las Partes no logran un curso de reparación. ${ }^{39}$

En el Protocolo Modificatorio se trata de manera desigual a México respecto a Estados Unidos en cuanto a los requisitos que se deben de cumplir para someter una controversia ante el MLRR, por las razones que a continuación se exponen.

Una Parte (Estados Unidos o México) puede presentar una reclamación si tiene un "fundamento de buena fe para creer" que está ocurriendo una Denegación de Derechos en una Instalación Cubierta. ${ }^{40}$

Artículo 31 A.2 del Protocolo Modificatorio:

39 Artículo 31 A.4.10 del Protocolo Modificatorio.

40 Este requisito se reitera en el artículo 31-A.4 del Protocolo Modificatorio. "Si una Parte reclamante tiene un fundamento de buena fe para creer que está ocurriendo una Denegación de Derechos en una Instalación Cubierta... podrá solicitar la integración de un Panel Laboral de Respuesta Rápida...”.
El Mecanismo aplicará siempre que una Parte (la "Parte reclamante") considere de buena fe que a los trabajadores de una Instalación Cubierta les ha sido negado el derecho de libre asociación y negociación colectiva...

Sin embargo, en el Protocolo Modificatorio se establece un requisito adicional para México ${ }^{41}$, ya que este solo puede presentar una reclamación ante un MLRR bajo una orden de ejecución de la National Labor Relations Board (Junta Nacional de Relaciones Laborales), conforme a lo escrito con letra chica en la Nota 1 del artículo 31 A.2 del Protocolo Modificatorio:

Con respecto a los Estados Unidos, una reclamación únicamente puede presentarse con respecto a una presunta Denegación de derechos debidos a los trabajadores en una Instalación Cubierta bajo una orden de ejecución de la Junta Nacional de Relaciones Laborales (National Labor Relations Board)...

Adicionalmente, para que la Denegación de Derechos en Instalaciones Específicas se considere un incumplimiento debe afectar el comercio o la inversión entre las

41 Lo mismo sucede en el caso de una Instalación Cubierta de Canadá, ya que México solo puede presentar una reclamación ante el Mecanismo de Respuesta Rápida bajo una orden de ejecución de la Junta de Relaciones Industriales de Canadá, Nota 1 del artículo 31-B.1 del Protocolo Modificatorio. 
partes y un MLRR supondrá (asumirá) que afecta el comercio o la inversión entre las partes, a menos que la parte demandada demuestre lo contrario, conforme a lo escrito con letra chica en la Nota 4 del artículo 23.3 del Protocolo Modificatorio. ${ }^{42}$

Para efectos de la solución de controversias, un panel supondrá que un incumplimiento es de una manera que afecte el comercio o la inversión entre las Partes, a menos que la Parte demandada demuestre lo contrario [énfasis añadido].

Dejar a la "buena fe" y al "creer" de la Parte reclamante (Estados Unidos) la activación de un Mecanismo de Respuesta Rápida, aunado al hecho de que este debe suponer que la supuesta Denegación de Derechos afecta el comercio o la inversión entre las Partes, facilita a la parte solicitante la activación de un MLRR y la obtención de una resolución favorable.

El panel puede realizar una visita de verificación a la instalación cubierta (planta o empresa), previa aceptación de esta, en los siguientes casos:

42 Cada parte mantendrá en sus leyes regulaciones y prácticas, entre otros derechos, el de libertad de asociación y el reconocimiento efectivo del derecho de negociación colectiva. Artículo 23.3.(a) del T-MEC. Para efectos de la solución de controversias un panel supondrá (asumirá) que un incumplimiento (negación de derechos) es de una manera que afecte el comercio o la inversión entre las Partes, a menos que la Parte demandada demuestre lo contrario. Nota 5 del Protocolo Modificatorio.
1. A solicitud de Parte para resolver si la negación de derechos ha sido reparada, $\mathrm{y}$

2. A solicitud de parte o de oficio para determinar si ha habido una negación de derechos, cuando la parte reclamante solicita el Mecanismo de Respuesta Rápida, ya sea porque la parte demandada no lleva a cabo una Revisión Voluntaria o como resultado de esta rechaza la existencia de la negación de derechos. ${ }^{43}$

El Mecanismo de Respuesta Rápida debe resolver si ha habido una negación de derechos en un máximo 30 días posteriores a la constitución del panel o de la verificación, en su caso. Es pertinente destacar que este término para resolver la controversia es muy corto y no tiene precedente en ningún otro tratado comercial.

\section{Reparaciones y sanciones}

Cuando exista una Denegación de Derechos, la Parte reclamante, considerando la opinión del Mecanismo de Respuesta Rápida, podrá imponer medidas de reparación a una Instalación Cubierta o planta específica, las cuales pueden consistir en:

a) La suspensión del tratamiento arancelario preferencial a las mercancías producidas o manufacturadas en la empresa o planta señalada,

43 Artículos 31 A.5 y 31 A.7.10 del Protocolo Modificatorio. 
b) la imposición de sanciones sobre las mercancías manufacturadas en la empresa, o

c) la imposición de sanciones a los servicios suministrados por la empresa.

Cuando una Instalación Cubierta reincida por segunda ocasión en una Denegación de Derechos, la medida de reparación se podrá extender o ampliar a las empresas de su propiedad o bajo su control que fabriquen las mismas mercancías o presten iguales servicios acorde al artículo 31 A10.1:

Si una Instalación Cubierta reincide por tercera ocasión, la medida de reparación podrá consistir en la prohibición de entrada de mercancías producidas o servicios prestados por la empresa y por las empresas de su propiedad o que estén bajo su control, que fabriquen las mismas mercancías o presten iguales servicios. ${ }^{44}$

\section{Agregados laborales}

Como se había mencionado, el 13 de diciembre del 2019 el presidente Trump presentó para la aprobación del Congreso, vía fast track, con el carácter de Congressional Executive Agreement, tanto el Protocolo que sustituye el TLCAN por el T-MEC ${ }^{45}$ como el Protocolo Modificatorio. Ambos instru-

44 Artículo 31 A.10.1 del Protocolo Modificatorio.

45 El nombre para México es T-MEC y para Estados Unidos es USMCA: Agreement between the United States of America, the United Mexican States and Canada (USMCA). Acuerdo entre los Estados Unidos de América, los Estados Unidos Mexicanos y Canadá (USMCA). mentos fueron aprobados por el Congreso norteamericano ese mismo día, al expedir la United States-Mexico-Canada Agreement Implementation Act HR5430 (USMCA Implementation Act). ${ }^{46}$

Conforme a lo previsto en la Sección 721 del USMCA Implementation Act, (ley nacional), el Secretario del Trabajo norteamericano deberá contratar hasta cinco oficiales o empleados de tiempo completo (agregados laborales) y los asignará a su embajada o consulado en México para llevar a cabo, entre otras, las siguientes tareas: ${ }^{47}$

- Asistir al Comité Laboral Interagencial para monitorear y hacer cumplir las obligaciones laborales de México.

- Presentar al Comité Interinstitucional del Trabajo informes trimestrales sobre los esfuerzos realizados por México para cumplir con sus obligaciones laborales.

- Revisar la lista de sectores prioritarios para su monitoreo y sugerir la inclusión de otros sectores.

En los textos del T-MEC y del Protocolo Modificatorio del T-MEC firmados por México, Estados Unidos y Canadá no se con-

46 An Act to implement the Agreement between the United States of America, the United Mexican States and Canada attached as an Annex to the Protocol Replacing the North American Free Trade Agreement, 18/4/2020, H.R. 5430 (Enrolled Bill), One Hundred Sixteenth Congress of United States of America.

47 Sección 721 (Establecimiento) y Sección 722 (Deberes) del USMCA Implementation Act. 
templa la existencia de los mencionados agregados laborales ni sus funciones.

Inmediatamente después de la publicación del USMCA Implementation Act emitido por el Congreso norteamericano, en diferentes medios se difundió el desacuerdo del gobierno mexicano con los cinco agregados laborales y sus funciones, por considerarlo un agravio fruto de las decisiones políticas del Congreso y del Ejecutivo estadounidenses, los cuales habían sido rechazados por México durante las negociaciones bilaterales del nuevo tratado comercial. ${ }^{48}$

Las actividades consistentes en monitorear y hacer cumplir las obligaciones laborales de México, encomendadas a los agregados laborales en el USMCA Implementation Act, no corresponden a ninguna de las funciones diplomáticas o consulares enumeradas en la Convención de Viena sobre Relaciones Diplomáticas ni en la Convención de Viena sobre Relaciones Consulares.

En términos generales las funciones diplomáticas y consulares consisten en proteger en el Estado receptor los intereses, tanto del Estado que envía y de sus nacionales dentro de los límites del derecho internacional, fomentar el desarrollo de las relaciones amistosas y económica, comerciales, culturales y científicas entre ambos países, y enterarse e informar a su

48 Uscanga, Oscar. Rechaza México injerencia laboral, Periódico Reforma, 15 de diciembre del 2019, p. 7. gobierno por todos los medios lícitos de la situación comercial, económica, cultural y científica del Estado receptor.

Adicionalmente, las misiones diplomáticas tienen las funciones de representación y negociación del Estado acreditante ante el Estado receptor. Las oficinas consulares pueden realizar funciones distintas a las mencionadas, siempre y cuando no estén prohibidas por las leyes y reglamentos del estado receptor, el Estado receptor no se oponga y estén previstas en acuerdos o tratados internacionales suscritos entre el Estado que envía y el estado receptor. ${ }^{49}$

La función de hacer cumplir las obligaciones laborales de México es una actividad soberana que solo corresponde al Estado mexicano, por lo que la actividad de los agregados laborales viola las leyes y reglamentos de México. Las funciones encomendadas a los agregados laborales no están previstas en un acuerdo o tratado internacional suscrito entre Estados Unidos y México.

Además, las funciones consistentes en hacer cumplir las obligaciones laborales de México son muy amplias, pues, para tal efecto, los agregados laborales podrían pretender, entre otras actividades, realizar visitas de verificación a las empresas mexicanas para su monitoreo, con base en una ley extranjera (USMCA Implementation Act).

49 Artículos 5 de la Convención de Viena sobre Relaciones Consulares, DOF, 20 de febrero de 1965 y 3 de la Convención de Viena sobre Relaciones Diplomáticas, DOF. 03 de agosto de 1965. 
En consecuencia, el gobierno mexicano puede oponerse a que cualquier funcionario diplomático o consular extranjero, llámese agregado laboral o de cualquier otra forma, realice las funciones de monitorear y hacer cumplir las obligaciones laborales de México.

Además, al no existir un acuerdo con Estados Unidos sobre los referidos agregados laborales, México puede exigir que el número de miembros de la misión diplomática u oficina consular norteamericana sea razonable y normal, según sus circunstancias, condiciones y necesidades.

Por otro lado, Estados Unidos debe comunicar a México sus nombramientos, tanto del personal diplomático como consular (nombre, clase, categoría), llámense agregados laborales o de cualquier otro modo, y el gobierno mexicano puede declararlos persona non grata o no aceptable, antes de su llegada o del inicio de sus funciones y el gobierno estadounidense deberá retirar su nombramiento.

En cualquier momento, México puede comunicar a Estados Unidos que un miembro del personal de su misión diplomática o de su oficina consular (agregado laboral), es persona non grata o no aceptable, y sin tener que exponer los motivos de su decisión el gobierno estadounidense debe retirarlo en un plazo razonable, de lo contrario el gobierno mexicano puede no considerar a dicha persona miembro del personal diplomático o consular; ${ }^{50} \sin$ embargo, se reitera, el problema no radica en la persona o cargo que desempeña, llámese agregado laboral o de cualquier otro modo, sino en la función que realiza.

En consecuencia, México puede oponerse a que cualquier persona adscrita a la embajada o consulado norteamericano realice las funciones de hacer cumplir las obligaciones laborales de México y, por lo tanto, rechazar su nombramiento, no esperar a posteriormente declararlo persona non grata o no aceptable.

Lo anterior cobra relevancia si consideramos que, conforme al sistema jurídico norteamericano, lo que tiene validez para Estados Unidos es el texto del USMCA Implementation Act, ley nacional emitida por el Congreso estadounidense al aprobar el tratado comercial, y no el texto del T-MEC firmado con México.

Seguramente Estados Unidos ejercerá presión para que el gobierno mexicano autorice que los agregados laborales realicen sus funciones en México, bajo el argumento de que se debe cumplir el compromiso internacional aprobado por el Congreso norteamericano y plasmado en el USMCA Implementation Act.

El consentimiento del gobierno mexicano para que los referidos agregados laborales realicen las funciones encomendadas en una ley extranjera (USMA

50 Artículos 7, 9, 10 y 11 de la Convención de Viena sobre Relaciones Diplomáticas y 10, 19, 20, 23 y 24 de la Convención de Viena sobre Relaciondes Consulares. 
Implementation Act), en su caso, además de las repercusiones negativas para México en la materia comercial, sentaría un precedente muy negativo para casos futuros, pues Estados Unidos con base en su ley nacional exigirá a México el cumplimiento de compromisos no pactados, violando la soberanía del Estado mexicano.

\section{Conclusiones}

1. El conocimiento y la comprensión del alcance del nuevo tratado comercial (T-MEC) implica analizar con detalle, tanto el Protocolo que sustituye el TLCAN por el T-MEC como el Protocolo Modificatorio, con especial atención en lo escrito con letra chica en las notas al pie de página de este último.

2. Para efectos de un Panel (Panel Laboral General y un Mecanismo de Respuesta Rápida) la Parte demandada tiene la carga probatoria de demostrar un hecho negativo. El incumplimiento de una obligación laboral debe afectar el comercio y la inversión entre las Partes y un Panel supondrá que es así, a menos que la Parte demandada demuestre lo contrario.

3. Los requisitos para activar un MLRR son mayores para México que para Estados Unidos y Canadá, en su caso. Aun cuando el Protocolo Modificatorio establece que cualquiera de las partes puede solicitar un Mecanismo de Respuesta Rápida si tiene un "fun- damento de buena fe parta creer" que existe una negación de derechos en una instalación específica, México requiere una orden de ejecución de una agencia estadounidense o canadiense para presentar una reclamación. Existe el riesgo de iniciar procedimientos arbitrales sin sustento, lo cual representará una carga adicional de recursos económicos y humanos, tanto para la Parte demandada como para las empresas situadas en su territorio. Es muy probable que en la mayoría de los casos México sea la Parte demandada.

4. En el T-MEC no se pactaron los cinco agregados laborales adscritos en la embajada o consulado norteamericano para vigilar y hacer cumplir las obligaciones laborales de México. Estos carecen de fundamento y su aceptación sentaría un precedente muy negativo para que en casos futuros el gobierno estadounidense exija el cumplimiento de sus leyes en territorio mexicano.

\section{Referencias}

An Act to implement the agreement between the United States of America, the United Mexican States, and Canada attached as an Annex to the Protocol Replacing the North American Free Trade Agreement, april $18^{\text {th }}$, 2020, H.R. 5430 (Enrolled Bill). One Hundred Sixteenth Congress of United States of America.

Banco de México, Consideraciones sobre la Reforma Laboral de 2019. Extracto del Infor- 
me Trimestral enero-marzo 2019, Recuadro 4, pp. 35-37, mayo 2019.

BBC MUNDO. Redacción, Donald Trump retira a Estados Unidos del TPP, el Acuerdo Transpacífico de Cooperación Económica. https://www.bbc.com/mundo/noticias-internacional-38723381

Carrillo Huerta y otros, La renegociación del TLCAN y sus posibles impactos en el desarrollo regional del país. En: Las relaciones México-Estados Unidos en la coyuntura actual. Carrillo Huerta, Mario Miguel, Coordinador, Consejo Latinoamericano de Cincias (CLACSO), Puebla, México, 2017.

Cargill, Inc. C. México (Escrito de dúplica), CIADI, Mecanismo complementario, Washington, D.C., Caso Núm. ARB (AF)/05/20.08.2020. Cargill, Inc. C. México (Laudo), CIADI, Mecanismo complementario, Washington, D. C. Caso Núm. ARB (AF)/05/2. Fecha de envío a las partes: 18 de septiembre de 2009.

Castañeda, Jorge, El T-MEC y la reforma laboral, El Financiero, 12 de abril de 2019.

Convención de Viena sobre Relaciones Diplomáticas.

Convención de Viena sobre Relaciones Consulares.

Cruz Barney, Oscar, La Solución de controversias en materia laboral en el Tratado entre los Estados Unidos Mexicanos y los Estados Unidos de América y Canadá, Instituto de Investigaciones Jurídicas de la UNAM, Opiniones técnicas sobre temas de relevancia nacional, núm. 18, 2020.
Decisión Final del Panel Binacional sobre la imposición de cuotas compensatorias impuestas a las importaciones de Jarabe de Maíz de Alta Fructosa (JMAF) originarias de los Estados Unidos de América, 03 de agosto de 2001. Caso Mex-USA-98-1904-01.

Decreto Promulgatorio del Tratado Integral y Progresista de la Asociación Transpacífico, D.O.F. 29 de noviembre de 2018.

Decreto que aprueba el Protocolo por el que se sustituye el TLCAN por el T-MEC del 30 de noviembre del 2018, Senado de la República, D.O.F. 29 de julio de 2019.

Decreto por el que se reforman, adicionan y derogan diversas disposiciones de la Ley Federal del Trabajo, de la Ley Orgánica del Poder Judicial de la Federación, de la Ley Federal de la Defensoría Pública, del Instituto Nacional de la Vivienda para Trabajadores y de la Ley del Seguro Social, en materia de Justicia Laboral, Libertad Sindical y Negociación Colectiva. D.O.F. 01 de mayo de 2019. Decreto Promulgatorio del Protocolo que sustituye el TLCAN por el T-MEC, hecho en Buenos Aires, el 30 de noviembre de 2018; del Protocolo Modificatorio al T-MEC, hecho en la Ciudad de México el 10 de diciembre de 2019; de seis acuerdos paralelos entre el Gobierno de México y el Gobierno de Estados Unidos, celebrados por intercambio de cartas fechadas en Buenos Aires, el 30 de noviembre de 2018 y de dos acuerdos paralelos entre el Gobierno de México y el Gobierno de Estados Unidos, celebrados en la Ciudad 
de México, el 10 de diciembre de 2019, DOF, 29 de junio de 2020.

De la Rosa, Eduardo, Administración de Biden podría abrir casos contra México en T-MEC. Diccionario de la Lengua Española, Real Académia Española, actualización 2020. Informe del Órgano de Apelación del caso México-Medidas Fiscales sobre los refrescos y otras bebidas, WT/DS308/ $\mathrm{AB} / \mathrm{R}, 06.03 .2006$.

Kenneth Smith, Peródico Milenio, México, 11 de noviembre de 2020.

Ley Aduanera.

Protocolo Modificatorio al Tratado entre los Estados Unidos Mexicanos, los Estados Unidos de América y Canadá, Secretaría de Relaciones Exteriores, 11 de diciembre de 2019. https://www.gob. $\mathrm{mx} /$ sre/documentos/protocolo-modificatorio-al-tratado-entre-los-estados-unidos-mexicanos-los-estados-unidos-de-america-y-canada

Puyana, Alicia, Del Tratado de Libre Comercio de América del Norte al Acuerdo México-Estados Unidos-Canadá. ¿Nuevo capítulo de integración México Estados Unidos? El Trimestre Económico, vol. LXXXVII(3), núm. 347, julio-septiembre de 2020.

Reglas Generales de Comercio Exterior 2019.

Silva Silva, Jorge Alberto, "Relaciones del Tráfico Jurídico Internacional en el Derecho Mexicano del Trabajo", Primera edición, Academia Mexicana de Derecho Internacional Privado y Comparado, 2021, p. 255. http://.amedip.org/
Uscanga, Óscar. Rechaza México injerencia laboral, Periódico Reforma, 15 de diciembre del 2019.

Weller, Christian E. "The Future of North American Trade Policy. Lesson from NAFTA. Boston University", The Frederick S. Pardee Center for the Study of Longer-Range Future, November 2009. 